\title{
How New Businesses Can Improve Their Chances of Survival
}

\author{
Howard E. Aldrich (University of North Carolina at Chapel Hill)
}

\section{KEYWORDS: Information, Software, Data.}

More than five decades ago, celebrated sociologist Arthur Stinchcombe coined the term "liability of newness" to depict the disadvantages that new organizations face: they often appear less legitimate compared to established entities and they depend more heavily on cooperation from strangers.

Entrepreneurs must also overcome "liabilities of newness" in order to succeed, and this continues to be an area of intense interest among those who study entrepreneurship. In a recent longitudinal study we conducted, published in Social Science Research, we surveyed 1030 new ventures over six years to get a glimpse into organizations at their earliest stages, when such liabilities of newness loom the largest. We discovered something encouraging: that new businesses can improve their chances of survival if they simply do things that legitimate businesses do. In other words: go through the motions of incorporating, hiring an attorney or accountant, or joining a trade association, even if you're not sure you'll survive. Fake it and you are more likely to make it.

As expected, we found evidence of a heightened risk of failure for early-stage organizations: about half the organizing efforts failed during the course of the six-year survey. But we also found that by raising more resources, enacting routines, and establishing organizational boundaries, entrepreneurs can overcome the liabilities of newness.

Having money and experience conferred some initial advantages that improved the chance for survival. For example, consider these hypothetical examples: founders with ten years of work experience in the same industry as the startup reduce their odds of failure by $20 \%$, all else being equal, and founders who make an initial investment of $\$ 1000$ lower the odds of failing by $23 \%$. Having some initial investments likely enabled the founder to work on the venture fulltime, giving it the attention it needs to survive.

But our analyses showed that subsequent activities that businesses took after founding actually mattered more for firm survival than how they'd started out. In a nutshell, founders' attempts at organizing new businesses succeed to the extent that they go beyond their initial organizing conditions.

For instance, entrepreneurs who invested $\$ 4000$ additional financial capital after the initial funding were $30 \%$ less likely to abandon their startup. Kicking in more money after the venture is established helped make the initial investment immaterial: what truly mattered for survival was whether founders continued to invest after the first round, rather than stopping with just the initial investment.

We also found that enacting "organizational routines" -such as writing a business plan, retaining an accountant or lawyer, or signing an ownership agreement -- also reduced the hazard of failure anywhere from $26 \%$ to $46 \%$. Compared to raising additional financial resources, these discrete organizing events were much more significant. These activities were important, we believe, because they forced founders to think in a disciplined and systematic way about how they were going to run their new venture. Intuition and haphazard decisions were replaced by greater attention to the organizing process: what had to be accomplished to get the new business up and running.

Making a protracted effort to enact organizational boundaries also reduced the odds of failure. We are referring to actions by founders that signal to the outside world that their firm is a real entity and is beginning to stand on its own. As founders work on turning their new venture into a reality, they are simultaneously trying to convince others to take their new venture on its own terms, as a "real thing" that exists separate from themselves. We identified some actions that could provide such signals to others and then investigated how much they contributed to the survival of the organizing effort. Joining a trade association reduced a new venture's hazard rate by about $38 \%$, and being registered with a government agency or bureau by $27 \%$. 
Simply having the commitment to invest full-time effort into the venture also reduced the failure rate by $25 \%$. As our report states:

"We believe that investing significant amounts of time increases emerging organizations' survival because they indicate entrepreneurs' commitments to the venture's survival, spurring them to undertake organizing activities even before their businesses become profitable." Founders advance their cause by making a commitment and focusing on the organizing process. Such actions may strike some people as mundane, but they are the stuff of new venture organizing, rather than the occasional "hero" stories we read in the popular press. Organizing is hard work!

This study highlights the important fact that new ventures are not stuck with whatever they have initially assembled. Instead, during the organizing process, entrepreneurs can transform limited resources into organizations through action. Pursuing external resources, creating routines and standards, and establishing organizational boundaries can substantially increase the likelihood that their emerging ventures persist long enough to achieve a stable existence.

\section{The Takeaway:}

- New businesses' survival depends less on what founders bring to a startup than on how much they can learn during the organizing process. This study offers evidence that emerging organizations can survive - despite competitive and financial challenges - if entrepreneurs commit to undertaking a variety of business activities.

- Rather than enjoying positive momentum from initial financial investments, founders must invest additional resources after the first year to increase the odds of survival. However, financial capital alone is not sufficient to overcome the liability of newness: Additional increments of capital beyond $\$ 5000$ offered diminishing returns.

- Investing the time needed to get your business off the ground may just be the key to success. This study shows that entrepreneurial commitment is highly correlated with indicators of conducting subsequent business activities, which are in turn correlated with firm survival. In the end, it's not what you have, but what you put into it.

- Typical entrepreneurs begin on the same footing, with equal chances against the liability of newness. Experience in the same industry as the new venture mattered. but that was it. Although it seems counter-intuitive, in this nationally representative sample of typical new businesses, neither previous managerial experience, work experience outside the industry, or working with a prior founding partner or household partner played a role in firm survival. Essentially, everyone starts over if they want to become their own boss.

\section{References}

Yang, T., Aldrich, H.E., "The liability of newness" revisited: Theoretical restatement and empirical testing in emergent organizations, Social Science Research (2016), http://dx.doi.org/10.1016/j.ssresearch.2016.09.006 (http://dx.doi.org/10.1016/j.ssresearch.2016.09.006) 